\title{
Contribution of air and water to the carbon balance of Fucus spiralis
}

\author{
S. C. Maberly, T. V. Madsen* \\ Department of Biology and Preclinical Medicine, The Sir Harold Mitchell Building, The University, St. Andrews, Fife \\ KY16 9TH, United Kingdom
}

\begin{abstract}
A model was used to calculate the rate of carbon exchange by Fucus spiralis $\mathrm{L}$. in the field. The model combines laboratory measurements of the effect of photon irradiance, desiccation and temperature on photosynthesis and respiration in air and water, with a simulation of changes in tidal level over a lunar month, received photon irradiance for different coastal water types and fieldmeasured coefficients of water loss (D). The model predicts field growth rates of 1.3 and $2.1 \%$ (mol C $\mathrm{mol}^{-1} \mathrm{C} \mathrm{d}^{-1}$ ) in April and 2.1 and $4.8 \%$ in July for the highest and lowest values of $\mathrm{D}$, respectively. These values are in general agreement with published estimates of growth rates for $F$. spiralis in the field and laboratory. The net production per tide is very variable, even under the regular diurnal changes in photon irradiance used in the model. This is a result mainly of the length of time spent in light and dark per tide, but partly a response to whether F. spiralis is in air or water around midday, and whether maximal production is possible in air or water, which will depend largely on the value of $D$. The value of $\mathrm{D}$ was the major influence on total net production, and the relative contribution of air and water Under Jerlov's 'coastal 7 ' water type, net production when D was the lowest measured in the field was 1.6 and 2.3 times greater than that when $\mathrm{D}$ was the highest measured in the field for April and July respectively, but only 0.63 for April, and 0.53 for July, of that possible if desiccation was absent. In April, water contributed between 49 and $55 \%$ of the total net production for Jerlov's 'coastal 13' and 'coastal 1' water types when D was the lowest, and 82 and $84 \%$ for these water types when D was the highest measured in the field. Similar values for July are 23 and $28 \%$ when D was low and 56 and $63 \%$ when D was high. The effect of different coastal water types on total production was fairly small. Under field values of $D$, spring tides were between 1.85 and 2.3 times more productive than neap tides for both months. Production was calculated assuming F. spiralis was present at higher and lower positions on the shore. Under all conditions, except for the extreme case of no water loss, production decreased markedly higher up the shore, and increased down the shore, with maximal production between 1 and $3 \mathrm{~m}$ lower depending on conditions. These calculations reinforce the suggestions that the position of $F$. spiralis on the shore is not determined by carbon balance per se.
\end{abstract}

\section{INTRODUCTION}

Marine macroalgae which grow exposed in the intertidal region of the seashore spend, by definition, part of the time in air and part in water. They therefore experience 2 very different environments for photosynthesis and growth (Maberly \& Spence 1989). In particular, the aerial environment presents problems of water loss, nutrient uptake for haptophytes, and possibly high light levels, while the aquatic environment poses problems of lower light levels and possibly a restricted supply of inorganic carbon given the low rate of diffu-

\footnotetext{
- Present address: Botanical Institute, 68 Nordlandsvej, DK8240 Risskov, Denmark
}

sion of $\mathrm{CO}_{2}$ in water. For intertidal species, the timing of exposure to air and water interacts with the timing of exposure to light and dark to produce a very variable environment for photosynthesis and respiration. Air frequently is thought to be the less favourable of the 2 environments for photosynthesis and growth of many intertidal macroalgae. Thus, for example, desiccation in air is thought to be an important environmental factor which restricts the upshore extension of many species (Schonbeck \& Norton 1978). Laboratory measurements of net photosynthesis have shown, however, that for some species at least, rates may be greater in air than in water (e.g. Fucus distichus, Johnson et al. 1974, Quadir et al. 1979; Endocladia muricata, Porphyra perforata, and Iridaea flacca, Johnson et al. 1974). These data were obtained under limited, or in 
the absence of, desiccation and so represent the potential for rapid photosynthesis in air. Desiccation in the field could markedly reduce the rates, and thus reduce the importance of air to the carbon-balance of intertidal macroalgae.

In the absence of any direct measurements of the relative importance of air and water in the overall carbon balance of an intertidal species, an alternative approach has been to combine laboratory measurements of the response of the alga to relevant environmental conditions, with field measurements of these variables over time using a model. Thus, Beer \& Eshel (1983) combined information on the effect of water content on the rate of photosynthesis with rates of water loss in the field for Ulva sp. on one day to estimate the extent to which desiccation in air would reduce rates of photosynthesis in the field assuming light saturation. Oates (1985) calculated production during daylight in air and water for the saccate Phaeophyta Colpomenia peregrina, by multiplying the number of hours in each medium by the light-saturated rate. Thalli of this species lose little water in air because they have access to retained water, and so it was not necessary to take the effect of desiccation into account. A similar approach was used by Oates (1986) for another saccate species, Halosaccion americanum.

Fucus spiralis L. is an upper-shore intertidal alga which, like the bulk of intertidal species, is not saccate. The effects of photon irradiance, temperature and water loss on rates of photosynthesis and respiration in air and water have been described by Madsen \& Maberly (1990). These data give an opportunity to model the relative importance of air and water in the carbon balance of this species, and the relative effects of desiccation in air and light attenuation underwater on productivity.

\section{MATERIALS AND METHODS}

Rates of water loss in the field. Apices of Fucus spiralis of similar appearance and a length of about $5 \mathrm{~cm}$ were collected from the field site at the Hind Rock, St. Andrews, UK $\left(50^{\circ} 20^{\prime} \mathrm{N}, 2^{\circ} 47^{\prime} \mathrm{W}\right)$ the previous day. They were allowed to hydrate fully in aerated seawater for at least $12 \mathrm{~h}$ at $15^{\circ} \mathrm{C}$ and $200 \mu \mathrm{mol} \mathrm{m} \mathrm{m}^{-2} \mathrm{~s}^{-1}$ (PAR, 400 to $700 \mathrm{~nm}$ ) under a $16 \mathrm{~h}$ day. On 6 occasions in July 1987. 20 apices were laid out on the Hind Rock, just above the level at which F. spiralis is found. Every $20 \mathrm{~min}$ for 200 min, 2 apices were collected, placed in plastic bags and kept in the dark. At the same time, measurements were made of the air temperature and relative humidity immediately above the apices using wet and dry bulbs in a ventilated psychrometer. Thallus temperature was measured using a copper-constantan thermocouple connected to a meter. A solarimeter, $1.7 \mathrm{~km}$ away from the shore, recorded integrated values of total $\mathrm{Jm}^{-2}$ every 30 min. These values were converted to photon irradiance, PAR, using an empirical factor of $1.983 \mu \mathrm{mol}$ $\mathrm{m}^{-2} \mathrm{~s}^{-1}(\mathrm{PAR}) / \mathrm{Jm}^{-2}$ (total) determined by direct comparison, under a range of sky conditions, between the solarimeter and the quantum sensor used in the determination of photon irradiance in the photosynthesis experiments (Madsen \& Maberly 1990).

On return to the laboratory the apices were weighed to determine their 'desiccated weight' and placed in aerated seawater for at least $12 \mathrm{~h}$ as before, to fuily hydrate before being re-weighed to determine their 'fully-hydrated weight'. The apices were dried at $80^{\circ} \mathrm{C}$ for $24 \mathrm{~h}$ and weighed to determine their dry weight. Percent water content was determined from:

$W \%=\frac{\text { (desiccated weight }- \text { dry weight) }}{(\text { fully-hydrated weight }- \text { dry weight) }} \times 100$

Description of the model. Equations and data which described tide height, available light, rates of water loss and rates of photosynthesis and respiration of Fucus spiralis were incorporated into a programme, written in Basic, which ran on a micro-computer. The physiological data were collected in May and June, and calculations were made for adjacent months. April was chosen as a month where air and water temperature were both low, and in July both were high.

Tide height and time: The model assumes that 57 tides occur within a lunar synodic month of $29.531 \mathrm{~d}$ and that each tide has an equal duration of $12.432 \mathrm{~h}$. The sequence was located in time by starting at low water for the spring tide following a full moon. The average time of water for this tide for the appropriate standard port of Leith corrected for the nearest secondary port. 'Anstruther Easter' $(24 \mathrm{~km}$ around the coast from St. Andrews), is at 21:30 h.

For each of the 57 tides, the height of the low and high water was determined from the mean of 3 lunar months (between January and March 1985) for Leith. This therefore took into account inter alia the fact that the low water in the afternoon is lower than that in the morning. The height of mean high water of spring and neap tides, mean low water of spring and neap tides and mean tidal level calculated by the model differed by between 0.03 and $0.08 \mathrm{~m}$ from the mean values for Leith given in the Admiralty Tide Tables (1984).

During each tide, tidal level (referred to Chart Datum) was calculated 48 times at an interval of $0.259 \mathrm{~h}$, using the spring and neap tide curves for Leith. It was assumed that tides intermediate between spring and neap had linearly intermediate tidal curves. The height of Fucus spiralis at the Hind Rock was located to tidal level by surveying to a benchmark $0.4 \mathrm{~km}$ away 
The mid-point of the F. spiralis zone occurred at $4.41 \mathrm{~m}$ above Chart Datum.

Light: When Fucus spiralis is underwater, the surface irradiance will be reduced. Surface reflection was assumed to equal $10 \%$ and attenuation coefficients $(\mathrm{K})$ for 7 wavelengths at $50 \mathrm{~nm}$ intervals between 400 and $700 \mathrm{~nm}$ for coastal water types 1, 3, 5, 7 and 9 were obtained from Jerlov (1976); values in Dring (1987) were used for the extrapolated coastal water types 11 and 13 .

For each of the 7 wavelengths, the partial daily irradiance $\left(I_{p}\right)$ was calculated from:

$$
I_{p}=e^{\left(\log _{e}\left(0.9 I_{\Sigma}^{0} / \vec{p}\right)-K z\right)}
$$

where I ${ }^{\mathrm{g}}$, the daily irradiance at the surface, was assumed to comprise all wavelengths between 400 and $700 \mathrm{~nm}$ equally, so that the daily irradiance at depth $\mathrm{z}$, Iz was calculated from the sum of these values.

The photon irradiance received by Fucus spiralis at any time over the average day $\left(\mathrm{I}_{\mathrm{t}}\right)$ was calculated from the average daily irradiance $\left(I_{\Sigma}\right)$ which equalled $I_{\Sigma}^{\circ}$ when $F$. spiralis was in air and $\mathrm{I}_{\Sigma}^{z}$ when in water, the daylength $(\lambda)$ and the time from noon ( $t)$, following the approach in Maberly (1985):

$$
I_{t}=\left(I_{\Sigma} / \lambda\right)(1+\cos (2 \pi t / \lambda))
$$

Fifteen-year average values of surface daily irradiance for April and July were obtained from a solarimeter at Invergowrie, Dundee, about $22 \mathrm{~km}$ away. These values were converted to PAR as described above.

Photosynthesis and respiration in air: Rates of net photosynthesis in the light (P) and respiration in the dark $(R)$, in air, were calculated using the equations and data in Madsen \& Maberly (1990) for assumed constant air temperatures of 10 and $20^{\circ} \mathrm{C}$ for April and July respectively. Data from the Meteorological Office, Edinburgh, for Leuchars ( $7 \mathrm{~km}$ away) between 1974 and 1980 show that mean night-time temperatures were 1.6 and $2.1^{\circ} \mathrm{C}$ below respective daily averages for April and July. Mean daytime temperatures were 1.0 and $0.9^{\circ} \mathrm{C}$ above the respective daily averages for the same months. This diurnal variation in temperature was not taken into account in the model.

The rate of gross photosynthesis ( $\mathrm{P}^{\mathrm{gross}}$ ) as a function of photon irradiance was described by the Smith (1936) equation:

$$
\mathrm{P}^{\text {gross }}=\mathrm{P}_{\max }^{\mathrm{gross}} \alpha \mathrm{I}_{\mathrm{t}} /\left(\mathrm{P}_{\max }^{\text {gross }}{ }^{2}+\left(\alpha \mathrm{I}_{\mathrm{t}}\right)^{2}\right)^{1 / 2}
$$

where $\mathrm{P}_{\max }^{\mathrm{gross}}$ is the maximum rate of gross photosynthesis at light saturation and $\alpha$ is the initial slope of $\mathrm{P}$ against $I$.

The percent water content ( $\mathrm{W} \%$ ) at any time (min) since the plants emerged into air $\left(t_{E}\right)$ is a function of the coefficient of water loss (D):

$$
\mathrm{W} \%=100 \mathrm{e}^{-(\mathrm{DtE})}
$$

The proportional reduction in the rates of net photosynthesis $\left(P_{w}\right)$ and respiration $\left(R_{w}\right)$ by reduced water content was described by equations in Madsen \& Maberly (1990):

$$
\begin{aligned}
& P_{w}=(1.5 W \%-23.6) / 100 \\
& R_{w}=(1.09 W \%-2.4) / 100
\end{aligned}
$$

These equations were modified so that $P_{w}$ and $R_{w}$ did not exceed 1.0 .

The rate of net photosynthesis (P) at a given water content was calculated from:

$$
P=\left(P^{\text {gross }} P_{w}\right)-\left(R R_{w}\right)
$$

Photosynthesis and respiration in water: Rates of net photosynthesis in the light and respiration in the dark were calculated using the equations of Madsen \& Maberly (1990) for an assumed constant temperature of $10^{\circ} \mathrm{C}$ in April and $15^{\circ} \mathrm{C}$ in July. The effect of light on gross photosynthesis was described by the Smith (1936) equation (Eq. 4).

On return to water following desiccation in air, photosynthesis took up to $35 \mathrm{~min}$ to reach maximum rates (Madsen \& Maberly 1990). The proportion of net photosynthesis during recovery $\left(\mathrm{P}_{\mathrm{r}}\right)$ to maximum rates at a time $(\mathrm{min})$ since re-submergence $\left(\mathrm{t}_{\mathrm{s}}\right)$ was described by:

$$
P_{r}=\left(1-P_{w}\right)\left(1-e^{-0.0961 \eta}\right)+P_{w}
$$

The similar proportion of recovery of respiration rate $\left(R_{r}\right)$ was not measured, but was assumed to follow a similar pattern:

$$
R_{I}=\left(1-R_{w}\right)\left(1-e^{-0.0961 t_{v}}\right)+R_{w}
$$

When $t_{s}$ was greater than $35 \mathrm{~min}, \mathrm{P}_{\mathrm{r}}$ and $\mathrm{R}_{\mathrm{r}}$ equal 1 . The rate of net photosynthesis in water was calculated from:

$$
\mathrm{P}=\left(\mathrm{P}^{\text {gross }} \mathrm{P}_{\mathrm{r}}\right)-\left(\mathrm{R} \mathrm{R}_{\mathrm{r}}\right)
$$

\section{RESULTS}

\section{Rates of water loss}

Percent water content (W\%) followed an exponential decrease with time of exposure (data not shown). Linear regressions were performed on $\log _{e} \mathrm{~W} \%$ against time (min) in order to determine the coefficients of water loss (D) with units $\log _{e} \mathrm{~min}^{-1}$. There was a 4 -fold variation in $\mathrm{D}$ over the 6 occasions when measurements were made (Table 1). The highest and lowest values of $\mathrm{D}$ were used in the model to delineate the likely extremes of $\mathrm{D}$ to be found in the field. 


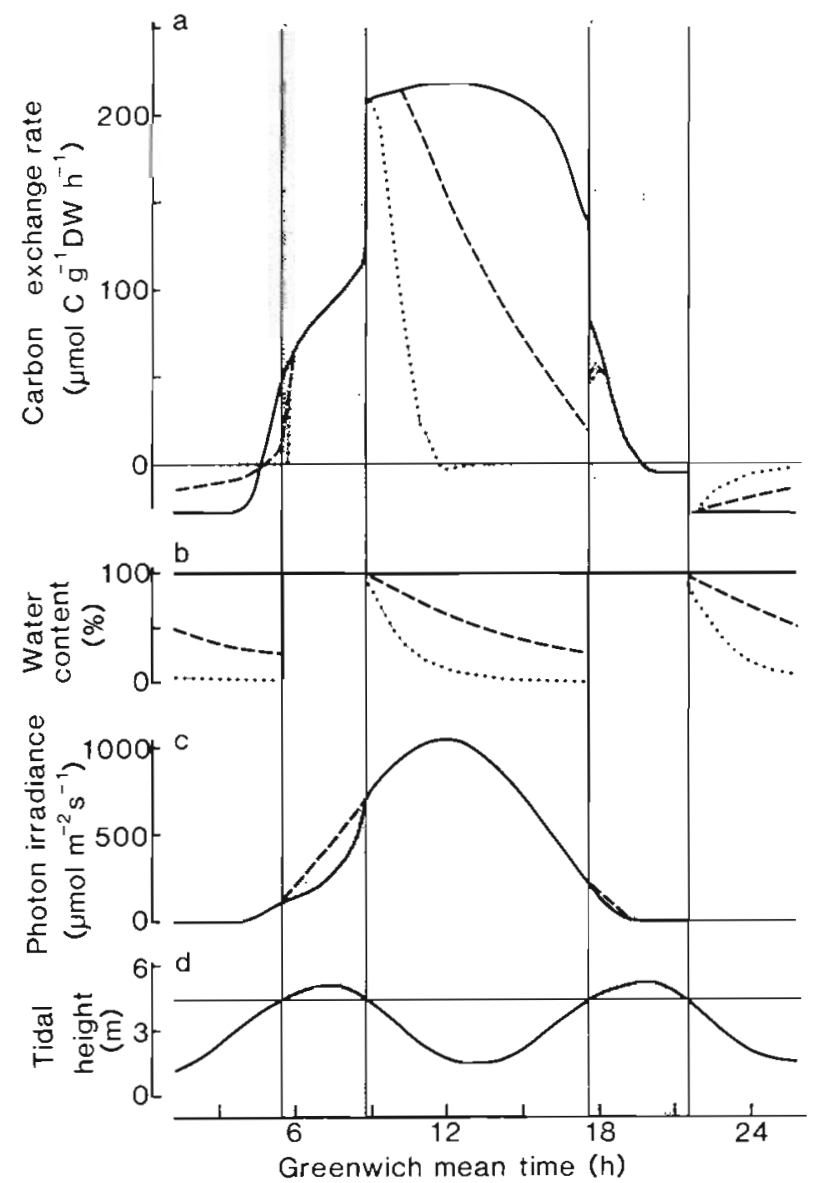

Fig. 1. Example of output from the model in July for the 9th and 10 th tide after spring tides and 'coastal 7 ' water. Stippled area indicates time underwater. (a) Rates of carbon exchange for the highest $\left(10.96 \times 10^{-3} \log _{\mathrm{e}} \mathrm{min}^{-1}\right)(\ldots)$ and lowest $(2.54$ $\left.\times 10^{-3} \log _{\epsilon} \mathrm{min}^{-1}\right)(---)$ coefficients of water loss measured in the field, and also for no water loss (_- ) (b) Percent water content for the highest (...), lowest (-..) and no water loss $(-)$. (c) Photon irradiance received ( - ) and also that at the surface (----). (d) Tidal level. Horizontal line represents the position of Fucus spiralis

The predicted carbon balance over the lunar month, expressed as the average daily carbon exchange, shows that in April, water is the major source of carbon when $D$ is high, but air and water contribute about equally when $D$ is low (Table 3). In July, water and air contribute about equally to the daily production when $\mathrm{D}$ is high, but air is most important when $\mathrm{D}$ is low. Net carbon gain in air was 4.5 and 4.8 times higher under low compared to high values of D for April and July respectively, and total net production was 1.6 and 2.3 times greater. If desiccation was absent, daily production would be substantially higher, particularly in July when high air temperatures allow potentially high rates of photosynthesis. Carbon loss at night is reduced when $D$ is high, but this beneficial effect on the carbon balance is small compared to the adverse effect on carbon gain during the day. Carbon gain in water is slightly affected by the rate of water loss, through its influence on recovery after an episode of desiccation.

Fig. 3a shows the effect of different coefficients of water loss on daily net production for the 2 extreme coastal water types. The clear 'coastal 1' water allows only slightly greater production than the extremely turbid 'coastal 13 ' water. In April, the percent contribution of water to the total daily net production ranged between 49 and $55 \%$ for coastal 13 and 1 water types respectively when $\mathrm{D}$ was the lowest measured, and between 82 and $84 \%$ when D was the highest measured in the field (Fig. 3b). In July, water contributed 23 and $28 \%$ for coastal 13 and 1 water types respectively when $\mathrm{D}$ was the lowest measured, and 56 and $63 \%$ when $\mathrm{D}$ was the highest measured in the field (Fig. 3b).

The contribution of air and water to the carbon balance will depend on the average rates of photosyn-

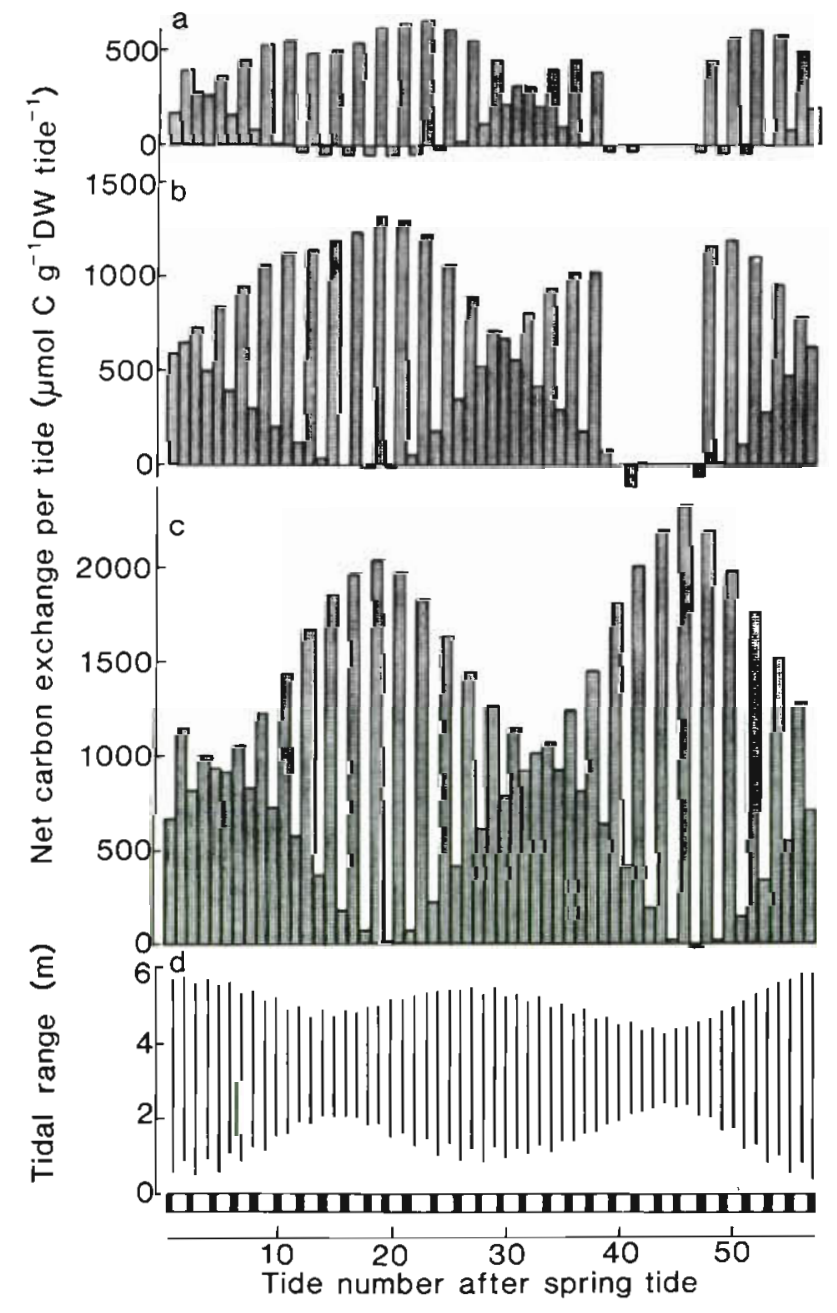

Fig. 2. Net production for each of the 57 tides during the lunar month. Calculated for July, a 'coastal 7 ' water type and 3 coefficients of water loss: (a) $D=10.96 \times 10^{-3}$; (b) $D=2.54 \times$ $10^{-3}$; (c) $\mathrm{D}=0 \log _{e} \mathrm{~min}^{-1}$ Tidal range (d) and the duration of dark and light periods are shown at the foot of the figure 
Table 3. Fucus spiralis. Average daily carbon exchange ( $\left.\mu \mathrm{mol} \mathrm{C} \mathrm{g}^{-1} \mathrm{DW} \mathrm{d} \mathrm{d}^{-1}\right)$ over a lunar month for the highest $\left(10.96 \times 10^{-3}\right.$ loge min $\left.^{-1}\right)$ and lowest $\left(2.54 \times 10^{-3} \log _{e}\right.$ min $\left.^{-1}\right)$ coefficients of water loss measured in the field, and also for no water loss. Calculated for 'coastal 7 ' water type

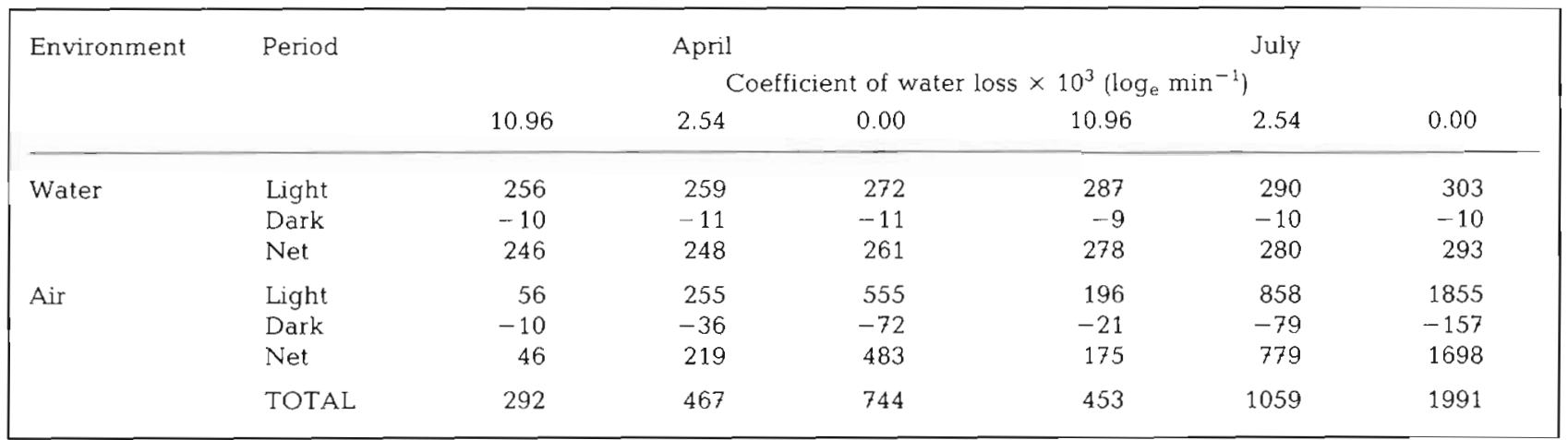

thesis and the length of exposure to each medium. On average over the lunar month, Fucus spiralis spends $18.2 \mathrm{~h}$ in air compared to $5.8 \mathrm{~h}$ in water every $24 \mathrm{~h}$ (Table 4). Average rates of photosynthesis in water are greater than those in air under all possible coefficients of water loss in April. In July, average rates of photosynthesis in water are greater than or equal to those in air except for the hypothetical case of no water loss. The greater rates of photosynthesis in water in July occur despite the approximately 2 -fold greater rates of net photosynthesis possible in air at light saturation in the absence of desiccation (Table 2).

The relative effect of tidal regime on production within the lunar month was determined by dividing the 57 tides equally into spring, mean and neap on the basis of the mean range of each tide (i.e. the mean of low water to high water and high water to low water). In the absence of desiccation, neap tides contribute a large proportion of the total production in July as rates of photosynthesis in air are potentially high (Table 5). For both months, however, even the lowest coefficient of water loss measured in the field reduced substantially the proportion of net production contributed by neap tides. Spring tides may be between 1.85 and 2.3 times more productive than neap tides under low and high coefficients of water loss respectively for the 2 months.

The degree to which ambient light saturates production was assessed by re-calculating production so that $\mathrm{P}^{\text {gross }}$ in Eq. (4) equalled the light-saturated rate, $\mathrm{P}_{\max }^{\text {mass }}$ for air and water as appropriate, during daylight hours. Production in water is 62 and $60 \%$ of that possible if light was saturating for April and July respectively (data not shown). Production in air was 55 and $56 \%$ of saturating values when $\mathrm{D}$ was high, and 64 and $61 \%$ when $D$ was low, for April and July respectively (data not shown).

The average carbon exchange over a lunar month was calculated for 3 coefficients of water loss, assuming
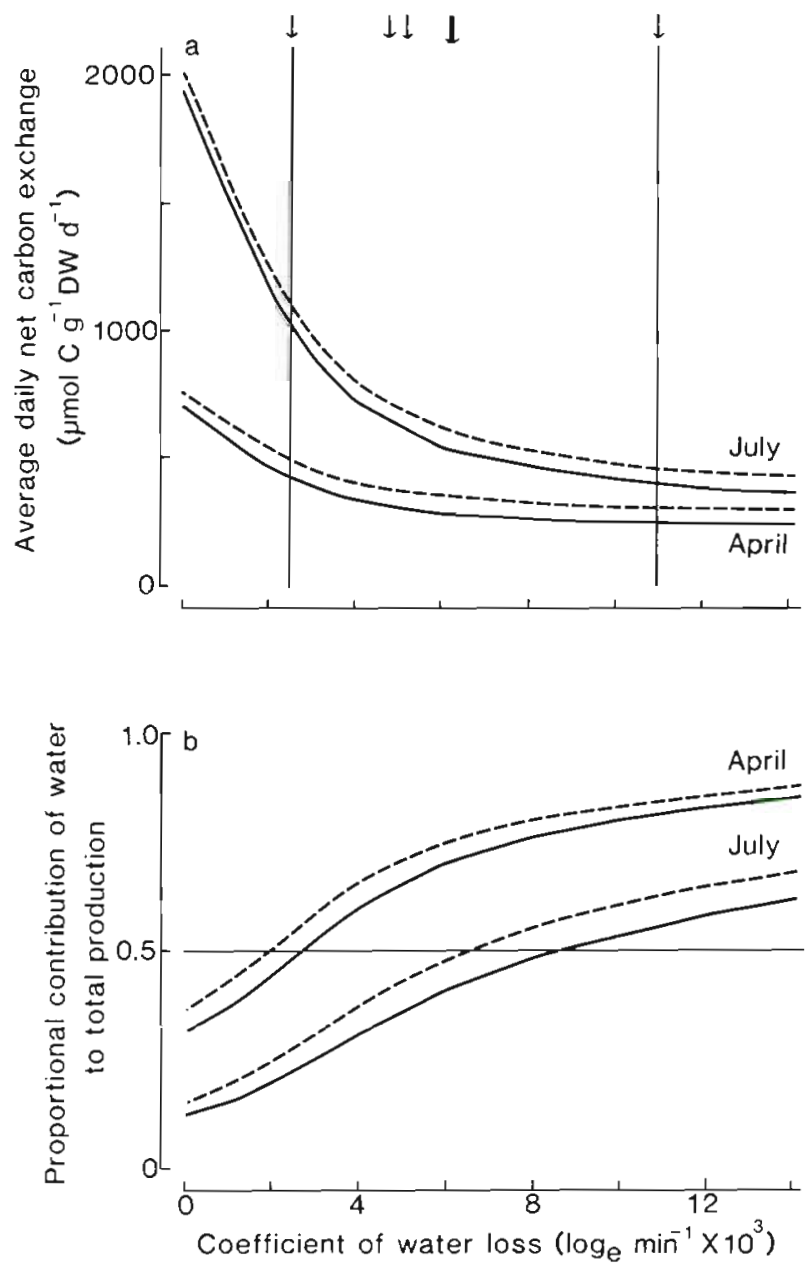

Fig. 3. Fucus spiralis. The effect of the coefficient of water loss (D) on: (a) total net production; (b) the contribution of water to total net production. Horizontal line indicates a contribution of $50 \%$. Calculated for April and July and 'coastal 1' (----) and coastal 13' (-) water types. Vertical lines indicate the minimum and maximum values of $D$ measured in the field: the other values are presented by vertical arrows 
Table 4. Fucus spiralis. Average rate of carbon exchange $\left(\mu \mathrm{mol} \mathrm{C} \mathrm{g}^{-1} \mathrm{DW} \mathrm{h}^{-1}\right)$ over a lunar month for the highest $\left(10.96 \times 10^{-3}\right.$ $\left.\log _{e} \min ^{-1}\right)$ and lowest $\left(2.54 \times 10^{-3} \log _{e} \mathrm{~min}^{-1}\right)$ coefficients of water loss measured in the field, and also for no water loss. Calculated for 'coastal 7 ' water type

\begin{tabular}{|c|c|c|c|c|c|c|c|c|c|}
\hline \multirow{3}{*}{$\begin{array}{l}\text { Environ- } \\
\text { ment }\end{array}$} & \multirow[t]{3}{*}{ Period } & \multicolumn{2}{|c|}{ Duration (h) } & \multicolumn{3}{|c|}{ April } & \multicolumn{3}{|c|}{ July } \\
\hline & & \multirow[t]{2}{*}{ April } & \multirow[t]{2}{*}{ July } & \multicolumn{6}{|c|}{ Coefficient of water loss $\times 10^{3}\left(\log _{e} \min ^{-1}\right)$} \\
\hline & & & & 10.96 & 2.54 & 0.00 & 10.96 & 2.54 & 0.00 \\
\hline \multirow[t]{2}{*}{ Water } & Light & 3.3 & 4.1 & 78 & 78 & 82 & 70 & 71 & 74 \\
\hline & Dark & 2.5 & 1.7 & -4 & -4 & -4 & -5 & -6 & -6 \\
\hline \multirow[t]{2}{*}{ Air } & Light & 10.5 & 12.5 & 5 & 24 & 53 & 16 & 69 & 148 \\
\hline & Dark & 7.7 & 5.7 & -1 & -5 & -9 & -4 & -14 & -20 \\
\hline
\end{tabular}

Table 5. Fucus spiralis. Percentage of total production over a lunar month contributed by spring, mean and neap tides for the highest $\left(10.96 \times 10^{-3} \log _{e} \min ^{-1}\right)$ and lowest $\left(2.54 \times 10^{-3} \log _{e} \min ^{-1}\right)$ coefficients of water loss measured in the field, and also for no water loss. Calculated for 'coastal 7 ' water type

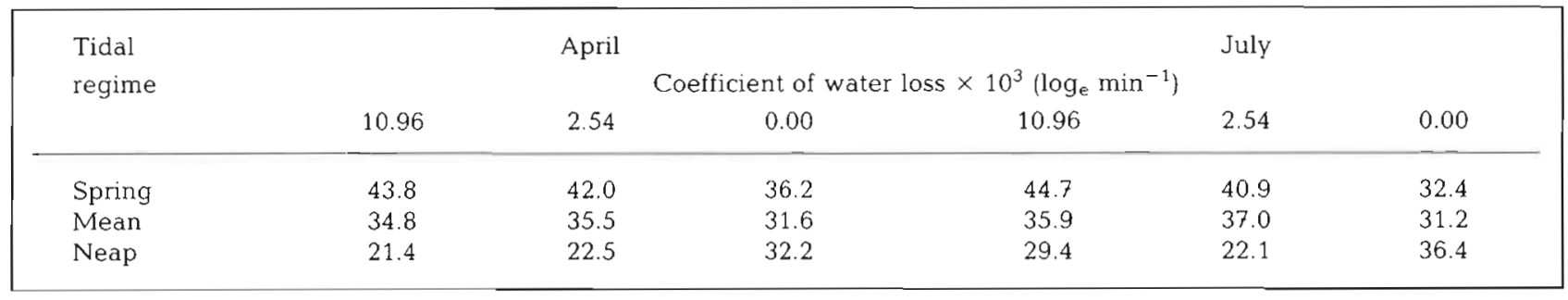

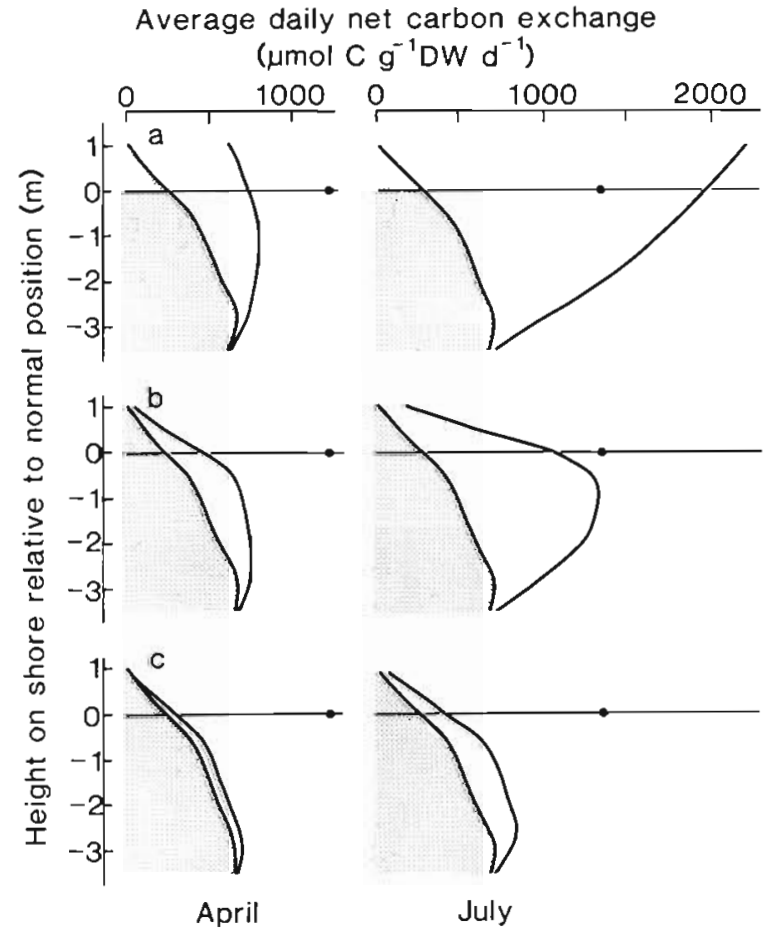

Fig. 4. Effect of position on the shore on average daily net production in water (stippled area) and air (open area): total production is the sum of these 2 areas. Calculated for 'coastal 7 ' water and 3 coefficients of water loss: (a) $\mathrm{D}=0$; (b) $\mathrm{D}=$ $2.54 \times 10^{-3} ;$ (c) $\mathrm{D}=10.96 \times 10^{-3} \log _{\mathrm{e}} \mathrm{min}^{-1}$. Horizontal line represents normal height of Fucus spiralis. Circles represent production possible if $F$. spiralis was in a pool at least $0.01 \mathrm{~m}$ below the water surface at its normal position on the shore that Fucus spiralis was present higher and lower on the shore than normal. The model predicts that production would be greater under nearly all conditions if $F$. spiralis was present lower down the shore with maximal production between 1 and $3 \mathrm{~m}$ lower depending on conditions (Fig. 4). In contrast, production would be markedly reduced if $F$. spiralis were 0.5 or $1.0 \mathrm{~m}$ higher (Fig. 4). If $F$, spiralis was in a pool at its normal position and $0.01 \mathrm{~m}$ below the water surface at low tide, then production would be increased over that possible when exposed to air during the tidal cycle (Fig. 4). This assumes, however, that other factors such as carbondepletion within the pool are not operating.

\section{DISCUSSION}

The calculated rates of carbon exchange based on the combination of laboratory and field data can be checked approximately by comparing literature values for the growth rate of Fucus spiralis with those calculated from the model. Niemeck \& Mathiesen (1978) present data which were used to calculate growth rates of $0.2 \%\left(\mathrm{~g} \mathrm{FW} \mathrm{g}^{-1} \mathrm{FW} \mathrm{d}^{-1}\right)$ in April and $0.4 \%$ in July in the field in New Hampshire, USA. F. A. Brown (unpubl., cited in Dring 1982, p. 125) measured growth rates of $1.5 \%\left(\mathrm{~g} \mathrm{FW} \mathrm{g}^{-1} \mathrm{FW} \mathrm{d}^{-1}\right.$ ) in September at Co. Down, Northern Ireland. In a laboratory experiment at $10^{\circ} \mathrm{C}$, a $16 \mathrm{~h}$ day and with seawater enriched with 
nutrients, $F$ spiralis had an average growth rate of $3.8 \%$ (g FW g ${ }^{-1} \mathrm{FW} \mathrm{d}^{-1}$ ) when continuously submerged (Schonbeck \& Norton 1980). The carbon balance data calculated here for 'coastal 7 ' water (Table 3) combined with a measured organic carbon content (wet-oxidation method) of $26.4 \% \mathrm{C} \mathrm{g}^{-1} \mathrm{DW}$ give predicted growth rates of 1.3 to $2.1 \%$ for April and 2.1 to $4.8 \%$ for July under high and low coefficients of water loss respectively. These values are more or less within the range of measured growth rates, although higher than those measured in the field. This presumably is because the physiological measurements of Madsen \& Maberly (1990) were made on active, apical pieces, and the model did not take into account biomass losses caused by factors such as attrition, grazing or gamete release, although the quantitative effect of these factors is not known.

Fucus spiralis is typically found towards the top of the zonation on rocky shores, beneath Pelvetia canaliculata. Unlike Pelvetia however, which is unable to tolerate continuous submergence (Rugg \& Norton 1987), downward extension of $F$. spiralis appears to be prevented by competition with faster-growing species. Schonbeck \& Norton (1980) found that F. spiralis had a greater linear growth rate when transplanted $0.85 \mathrm{~m}$ lower down the shore than when present at its normal position. The model predicts that production would be greater down to between 1 and $3 \mathrm{~m}$ lower, depending on conditions. The decline in production with declining height on the shore below this optimum position is a result of declining light availability. Like the model of Dring (1987), this model predicts a more or less linear decrease in light availability with declining height on the shore in the intertidal zone (data not shown). Net production would be markedly reduced if $F$, spiralis was higher up the shore than is normal. The fact that net production would still be possible suggests that the absence of $F$. spiralis from this zone could be explained by factors which affect survival such as periodic severe desiccation (Schonbeck \& Norton 1978). The greater production found when $F$. spiralis is continually submerged was calculated without taking improved nutrient availability into account (Schonbeck \& Norton 1979). Since the model predicts that net production would be possible throughout the intertidal region, the restricted distribution of $F$. spiralis in the field appears not to be the result of a restriction on carbon exchange per se.

The small effect of coastal water type on production is clearly a result of the shallow depth of water above Fucus spiralis, even at high tide. This contrasts with the results for macroalgae such as the Laminarians at the base of the intertidal or top of the subtidal where, using a model, Dring (1987) has shown that coastal water type has a large effect on available light and presumably on production.
Aerial leaves of amphibious freshwater macrophytes may increase productivity by giving these plants access to an environment of high light and constant availability of $\mathrm{CO}_{2}$ without suffering from water stress (Maberly \& Spence 1989). Saccate macroalgae such as Colpomenia peregrina have an internal reservoir of water which helps alleviate water loss and allows net photosynthesis to occur throughout the period of exposure to air (Oates 1985). Most intertidal macroalgae, however, are like Fucus spiralis in lacking means of restricting water loss or replacing lost water while in air. F. spiralis can photosynthesise more rapidly in air than in water at 15 to $20^{\circ} \mathrm{C}$ in the absence of desiccation (Madsen \& Maberly 1990), but in the field under most conditions water loss will reduce the rate of photosynthesis in air and may prevent photosynthesis for much of the daylight period. In the field, portions of thallus beneath overlying thalli may experience reduced water loss (Jones \& Norton 1979). Although this may have important implications for survival, the effect on productivity will be fairly small because a dry thallus only transmits $2.3 \%(\mathrm{n}=10, \mathrm{SD}=0.9 \%)$ of photosynthetically active radiation.

The model emphasizes the large effect that the coefficient of water loss, D, has on production. Even low values of $\mathrm{D}$ reduce production considerably compared to the hypothetical case of no water loss. Thus the potentially high rates of photosynthesis in air when temperature is high are reduced dramatically by desiccation.

Acknowledgements. We are grateful to Samantha Raines for expert assistance during the field work. We thank the Meteorological Office, Edinburgh and the Scoltish Crop Research Institute, Invergowrie for allowing us to use unpublished meteorological data. We thank Dr M. J. Dring for constructive comments on an earlier draft of the manuscript. T.V.M. received a grant from The Danish Natural Science Research Council.

\section{LITERATURE CITED}

Admiralty Tide Tabies (1984). Vol. 1. 1985. European waters including Mediterranean sea. The Hydrographer of the Navy

Beer, S., Eshel, A. (1983) Photosynthesis of Ulva sp. I. Effects of desiccation when exposed to air. J. exp. mar. Biol. Ecol. 70: 91-97

Drew, E A. (1983). Physiology of Laminaria. Ir Seasonal variation of photosynthesis and respiration in Laminaria digitata Lamour., L. hyperborea (Gunn.) Fosl. and L. SaCcharina (L.) Lamour. and a model for calculation of annual carbon budgets. P.S.Z.N.: I. Mar Ecol. 4: 227-250

Dring, $M$ J. (1982). The biology of marine plants. Arnold, London

Dring, M. J. (1987). Light climate in intertidal and subtidal zones in relation to photosynthesis and growth of benthic algae: a theoretical model. In: Crawford, R. M. M. (ed.) 
Plant life in aquatic and amphibious habitats. Blackwell Scientific Publications, Oxford, p. 23-34

Jerlov, N. G. (1976). Marine optics. Elsevier, Amsterdam

Johnson, W. S., Gigon, A., Gulmon, S. L., Mooney, H. A. (1974). Comparative photosynthetic capacities of intertidal algae under exposed and submerged conditions. Ecology 55: $450-453$

Jones, H. G., Norton, T A (1979). Internal factors controlling the rate of evaporation from fronds of some intertidal algae. New Phytol. 83: 771-781

Maberly, S. C. (1985). Photosynthesis by Fontinalis antipyretica. II. Assessment of environmental factors limiting photosynthesis and production. New Phytol. 100: 141-155

Maberly, S. C., Spence, D. H. N. (1989). Photosynthesis and photorespiration in freshwater organisms: amphibious plants. Aquat. Bot. 34: 267-286

Madsen, $T$ V., Maberly, S. C. (1990). A comparison of air and water as environments for photosynthesis by the intertidal alga Fucus spiralis L. J. Phycol., 26: 24-30

Niemeck, R. A., Mathiesen, A. C. (1978). Physiological studies of intertidal fucoid algae. Botanica mar 21: 221-227

Oates, B. R. (1985). Photosynthesis and amelioration of desiccation in the intertidal saccate alga Colpomenia peregrina. Mar. Biol. 89: 109-119

This article was presented by Dr M.J. Dring, Belfast, United Kingdom
Oates, B. R. (1986). Components of photosynthesis in the intertidal saccate alga Halosaccion americanum (Rhodophyta, Palmeriales). J. Phycol. 22: 217-223

Quadir, A., Harrison, P. J., De Wreede, R. E. (1979). The effects of emergence and submergence on the photosynthesis and respiration of marine macrophytes. Phycologia 18: 83-88

Rugg, D. A., Norton, T A (1987). Pelvetia canaliculata, a high-shore seaweed that shuns the sea. In: Crawford, $\mathrm{R}$. M. M. (ed.) Plant life in aquatic and amphibious habitats. Blackwell Scientific Publications, Oxford, p. 347-358

Schonbeck, M. W., Norton, T A. (1978). Factors controlling the upper limits of fucoid algae on the shore. J. exp. mar Biol. Ecol. 31: 303-313

Schonbeck, M. Norton, T. A. (1979). The effects of brief periodic submergence on intertidal fucoid algae. Estuar. coast. mar. Sci. 8: 205-211

Schonbeck, M. W., Norton, T A. (1980). Factors controlling the lower limits of fucoid algae on the shore. J. exp. mar. Biol. Ecol, 43: 131-150

Smith, E. L. (1936). Photosynthesis in relation to light and carbon dioxide. Proc. natn. Acad. Sci. U.S.A. 22: 504-511

Smithsonian Meteorological Tables (1951). Smithsonian miscellaneous collections 114,6 th edn. Smithsonian Institution, Washington

Manuscript first received: February 17, 1989

Revised version accepted: January 16, 1990 